\title{
The Combined Effects of Animal Products Intake and Physical Activity With Cause-specific and All-cause Mortality Among Patients With Type 2 Diabetes Mellitus in China: A Prospective Cohort Study
}

Chenlu He

Xuzhou Medical University

Hao Hou

Xuzhou Medical University

Yifei Pei

Xuzhou Medical University

Qian Chen

Xuzhou Medical University

Ying Zhang

Xuzhou Medical University

Jingjing Wang

Xuzhou Medical University

Jie Tang

Xuzhou Medical University

Na Yan

Xuzhou Medical University

Enchun Pan

Huai' an Center for Disease Control and Prevention

Zhongming Sun

Huai'an Center for Disease Control and Prevention

Peian Lou

Xuzhou Center for Disease Control and Prevention

Xunbao Zhang

Xuzhou Medical University

Wei Wang ( $\square$ weiwang90@163.com )

Xuzhou Medical University

\section{Research Article}

Keywords: Physical Activity, Diet, Mortality, Type 2 Diabetes, Cohort

Posted Date: January 3rd, 2022 
DOI: https://doi.org/10.21203/rs.3.rs-1210165/v1

License: (1) This work is licensed under a Creative Commons Attribution 4.0 International License. Read Full License 


\section{Abstract}

Background

To determine the associations of animal products intake and physical activity and their combined effects with cause-specific and all-cause mortality among type 2 diabetes mellitus (T2DM) patients in China.

Methods

Baseline data of 7311 type 2 diabetes mellitus (T2DM) patients recruited with a stratified random cluster sampling method were collected from December 2013 to January 2014. Participants were followed up until the date of their death or December 2019 for survivors, whichever came first. Nonlinear trends of cause-specific and all-cause mortality were assessed using restricted cubic splines with three knots placed at centiles 10,50, and 90 of diet intake. Cox proportional hazards models were used to estimate hazard ratios (HRs) and $95 \%$ confidence intervals (Cls) for the combined relationship of physical activity and animal products with causespecific and all-cause mortality.

\section{Results}

During a median follow-up of 6.1 years, 692 (9.5\%) T2DM patients died. The main cause of death was cardiovascular disease (CVD) (35.8\%), followed by cancer (20.6\%). After multivariable adjustment, a higher level of physical activity was nonlinearly associated with lower all-cause and CVD mortality in a J-shaped pattern, with the protective effect observed $>8 \mathrm{MET}$-h/d. Higher consumption of red meat, poultry, and aquatic products was associated with a lower risk of all-cause mortality ( $H R=0.75,0.64,0.75$, respectively, all $P<0.05)$. In the highest tertiles of physical activity, a higher intake of red meat, poultry, and aquatic products was associated with a lower risk for all-cause mortality than in the lowest tertiles (red meat, $H R=0.80,0.62,0.51$, and 0.48 ; poultry, $\mathrm{HR}=0.85,0.51,0.48$, and 0.45 ; aquatic products, $\mathrm{HR}=0.80,0.57,0.55$, and 0.40 , respectively). Similarly, the protective effect of moderate to high intake of poultry, aquatic products, and eggs on CVD mortality in high physical activity was found.

\section{Conclusions}

Our study highlights that in T2DM patients, better adherence to moderate to high consumption of animal products, including red meat, poultry, and aquatic products, together with engaging in moderate to high levels of physical activity exerts a beneficial effect in lowering cause-specific and all-cause mortality in China.

\section{Background}

Globally, type 2 diabetes mellitus (T2DM) has become the most widely known noncommunicable and common chronic endocrine multifactorial disease, and millions of people in developed and developing countries are affected [1]. As the social economy and way of life evolve, the prevalence of type 2 diabetes mellitus (T2DM) has been increasing in China [2, 3].

Diabetes is expected to impose a massive economic burden on individuals and countries around the world due to the high risk of mortality $[4,5]$. It has been confirmed that cardiovascular diseases (CVDs) [6], kidney 
failure [7], and some types of site-specific cancer [8] are the most common complications of T2DM that often arise together, which could collectively lead to a decline in life expectancy and even death [9].

Emerging evidence has demonstrated that diet and physical activity play important roles in the reduction of the mortality risk among T2DM patients $[10,11]$. These factors can not only decrease the prevalence of T2DM but also improve the survival rate of patients with T2DM. Substantial studies have placed great emphasis on the potential benefits of a high-quality protein diet in health management [12]. Recommended dietary patterns in many countries are rich in a variety of protein foods, including plant-based foods and animal products [13, 14]. There is compelling evidence that eating more plant-based foods, such as fruits, nonstarchy vegetables, whole grains, nuts, seeds, and legumes, is associated with a lower risk of disease morbidity and mortality [1416]. Humans obtain the majority of their protein from animal products, such as red meat, poultry, fish, and eggs [17]. However, in contrast to fish or beans, meat, particularly red or processed meat, is frequently regarded as unhealthy due to its high saturated fatty acid content $[18,19]$. The effects of certain animal products, such as red meat, poultry, fish, and eggs, on cause-specific and all-cause mortality in T2DM patients are still being studied.

Despite consistent evidence of links between processed/red meat consumption and health outcomes, it is unclear whether these links hold across levels of physical activity [20]. It is well known that exercise therapy is important for T2DM management. However, only $40 \%$ of T2DM patients engage in exercise therapy, and only $28.2 \%$ of patients complete the recommended amount of physical activity [21]. Through improved glycemic control, moderate to vigorous intensity physical activity (MVPA) could reduce the risk of CVD and all-cause mortality in patients with T2DM [22, 23]. Adults engaging in exercise who followed the 2018 physical activity guidelines for Americans exhibited greatly reduced risk of all-cause mortality, CVD mortality, and atherosclerotic CVD, including incident coronary heart disease, ischemic stroke, and heart failure [24, 25].

Although existing epidemiological studies have clearly assessed the relationship between animal products and physical activity with mortality separately in the general population [26, 27], little is known regarding the association of animal product intake and physical activity with mortality among patients with T2DM. For T2DM patients, their diet and lifestyle may differ in a variety of ways from those of patients without T2DM. High meat intake and a high level of physical activity might influence the effectiveness of medication treatments for T2DM. Thus, the current study aimed to evaluate the joint associations of animal product intake, including red meat, poultry, aquatic products, and egg intake, and physical activity with cause-specific and all-cause mortality in patients with T2DM in China.

\section{Methods}

\section{Participants and procedure}

The prospective cohort study "Comprehensive intervention and application of diabetes in the community" was carried out from December 2013 to January 2014 in Jiangsu Province to collect baseline diet data of T2DM patients. We used a stratified cluster random sampling method to obtain a representative sample including 30 towns/streets randomly selected from all towns/streets. According to resident health records in the essential public health service management system, a total of 9759 patients aged 18 years or older with diabetes residing in the selected towns or streets were enrolled in the study. 
After excluding participants with missing values of questionnaires, 7311 people were successfully included in the final analysis, yielding an excellent response rate of 74.9\%. Participants were followed up until December $31,2019$.

\section{Data collection}

Standard questionnaires were administered by well-trained staff to collect information concerning demographic characteristics (age, sex, educational level, marital status, household income, duration of diabetes, and $\mathrm{HbA} 1 \mathrm{c}$ ), health-related behaviors (frequency of smoking, frequency of drinking, physical activity, and sleep duration), and related complications (overweight or obesity, hypertension, dyslipidemia, stroke, coronary heart disease, and kidney disease).

\section{Covariates assessment}

T2DM was defined as FPG $\geq 7.0 \mathrm{mmol} / \mathrm{L}$ on at least two separate occasions by previous physician diagnosis or use of medication according to the 2010 diagnostic standard of the American Diabetes

Association [28]. Body mass index (BMI) was calculated as weight in kilograms divided by the square of height in meters and divided into four levels: BMl<18.5 (underweight), 18.5 $\leq \mathrm{BMl}<24.0$ (normal weight),

$24.0 \leq \mathrm{BMl}<28.0$ (overweight), and $\mathrm{BMI} \geq 28.0$ (obesity). For this study, the current definitions were used: never smoker, was not smoking at the time of the interview and answered "NO" to the question "Have you smoked at least 100 cigarettes in your life?". Based on answers to “Do you now smoke cigarettes (yes, no)?”, respondents were categorized into former or current smokers. Never alcohol drinker involved not drinking at the time of the interview and a "NO" answer to the question "Have you ever drunk in your life?". Current alcohol drinker involved drinking in the past 30 days. Former alcohol drinker referred to drinking in the past 12 months but no drinking in the past 30 days.

\section{Dietary intake assessment}

Dietary intake was evaluated through a validated food frequency questionnaire (FFQ) by trained investigators. Data on the average intake and frequency of various foods consumed in the last year were collected using a paper questionnaire. Information on the average daily intake of each kind of food, which included poultry meat, red meat, aquatic products, and eggs, was calculated (g/day).

\section{Physical activity assessment}

Physical activity information was obtained through the global physical questionnaire [29]. The level of physical activity was calculated using the met value of various physical activities and the duration and frequency of various activities. For each physical activity group, participants who reported no physical activity were first classified as zero physical activity, with the remainder divided into tertiles of level of physical activity: Iow level (first tertile), moderate level (second tertile), and high level (third tertile).

\section{Outcome assessment}

The primary outcomes were cause-specific and all-cause mortality. We followed up on the participants' vital status from the baseline survey to December 31, 2019. The mortality data were obtained through their linkage 
with the Chinese cause-of-death surveillance system, which records the date of death and the underlying cause of death with the International Classification of Diseases, Tenth Revision. The endpoint of our study was cause-specific mortality, including E10-E14 [30].

\section{Statistical analysis}

Baseline characteristics are presented as medians and interquartile ranges (nonnormally distributed continuous variables) and frequencies and percentages (categorical variables). For each participant, follow-up time was defined as the time from December 2013 until the date of death or December 2019 for survivors, whichever came first.

Combinations of the categories of intake of various foods and physical activity were used to jointly classify study participants into nine strata. Patients at the lowest level of physical activity and in the lowest category of intake of four kinds of foods were used as the reference category in these analyses.

We performed a nonlinear dose response analysis to explore the association between red meat, poultry, aquatic products, and egg intake, physical activity, and dietary factors with cause-specific and all-cause mortality using restricted cubic splines with three knots placed at the 10th, 50th, and 90th percentiles, with intake of red meat, poultry, aquatic products, and egg and physical activity as continuous variables [31].

Multivariable-adjusted Cox proportional hazards regression was used to estimate hazard ratios (HRs) and 95\% confidence intervals (Cls) for associations between red meat, poultry, aquatic products, and egg intake, physical activity, and dietary factors with cause-specific and all-cause mortality, respectively. All statistical analyses were performed using $\mathrm{R}$ version 4.0 .2 software. The 2 -tailed test was used, and $P<0.05$ was considered statistically significant.

\section{Results}

\section{Characteristics of the study sample}

Overall, the mean age of the cohort patients was 66.2 years (SD $=10.0$; range 21-92), and $38.3 \%$ of them were men. During a median follow-up of 6.1 years, 692 (9.5\%) T2DM patients died. The main cause of death was CVD (35.8\%), followed by cancer (20.6\%). Among deceased participants, their mean age at death was 68.7 years (SD = 8.8). In terms of health-related behaviors, current smokers and drinkers accounted for $23.0 \%$ and $18.0 \%$ of the sample, respectively. There were significant differences on all variables, except for frequency of drinking and kidney diseases ( $P>0.05$ ) (Table 1).

\section{Association between red meat, poultry, aquatic product, and egg intake and physical activity with mortality}

After multivariable adjustment, a higher level of physical activity was associated with a lower all-cause (HR = 0.64 95\% Cl 0.53-0.78) and CVD mortality (HR = 0.56 95\% Cl 0.40-0.79). For the consumption of red meat and poultry, a statistically significant inverse trend across quartiles was found $(P$ for trend $<0.001$; $P$ for trend $=$ 0.009). Higher consumption of red meat, poultry, and aquatic products was associated with a lower risk of allcause mortality $(\mathrm{HR}=0.7595 \% \mathrm{Cl} 0.59-0.95 ; \mathrm{HR}=0.6495 \% \mathrm{Cl} 0.51-0.81 ; \mathrm{HR}=0.7595 \% \mathrm{Cl} 0.59-0.95)($ Tables 2 and 3). 
As shown in Tables 3 and 4 , a high intake of poultry and aquatic products had a protective effect on the risk of CVD mortality ( $P \otimes 0.05)$. Such associations between egg consumption and all-cause mortality, CVD mortality, and cancer mortality were not observed.

\section{Dose-response relationships between red meat, poultry, aquatic product, and egg consumption and mortality}

Likewise, we observed nonlinear associations between red meat, poultry, and aquatic product consumption and all-cause mortality $(P$ for nonlinear $=0.032 ; P$ for nonlinear $<0.001 ; P$ for nonlinear $<0.001)$. The consumption of 42-194 g/day of red meat was significantly negatively associated with all-cause mortality. When the intake of poultry and aquatic products was 15-59 g/day and 23-41 g/day, respectively, the protective effects on all-cause mortality were significant. The lowest risk values were observed for the following kinds of foods: poultry (at $34 \mathrm{~g} /$ day, $\mathrm{HR}=0.71,95 \% \mathrm{Cl} 0.53-0.96$ ) and aquatic products (at $59 \mathrm{~g} /$ day, $\mathrm{HR}=0.78,95 \% \mathrm{Cl}$ 0.59-1.04). However, no significant association between eggs and all-cause mortality was observed (Fig. 1).

Nonlinear relationships for poultry and aquatic products with CVD mortality were observed $(P$ for nonlinear $=$ 0.046; $P$ for nonlinear=0.016). Moderate intake of red meat, poultry meat, aquatic products, and eggs was positively correlated with the risk of CVD mortality, but there were no significant differences (Fig. 1).

In addition, we also observed nonlinear associations between physical activity and poultry consumption and cancer mortality $(P$ for nonlinear $=0.019 ; P$ for nonlinear $=0.004)$. High intake of red meat, poultry, and aquatic products was positively related to the risk of cancer mortality, but there were no significant differences (Fig. 1).

\section{Hazard ratios of the combined effect of quartiles of red meat, poultry, aquatic product, and egg consumption and physical activity}

We cross-classified participants according to their joint exposures to diet (assessed with the quartile of average daily intake of each kind of food) and physical activity (three categories). The group of participants with the lowest intake of foods and lowest physical activity was used as the reference category.

Participants who engaged in high physical activity within each of the four categories of consumption of red meat exhibited a significantly reduced risk of mortality, with a downward trend from the lowest to the highest quartile $(\mathrm{HR}=0.8095 \% \mathrm{Cl} 0.58-1.11 ; \mathrm{HR}=0.6295 \% \mathrm{Cl} 0.44-0.88 ; \mathrm{HR}=0.51 ; 95 \% \mathrm{Cl} 0.33-0.80 ; \mathrm{HR}=0.4895 \% \mathrm{Cl}$ 0.31-0.74, respectively). There were similar trends in the intake of poultry and aquatic products (Fig. 2 and

\section{Supplementary Table1).}

Likewise, a reduced mortality risk was found among participants who consumed high amounts of red meat and any adherence to physical activity, particularly with a similar declining trend across quartiles of physical activity level $(\mathrm{HR}=0.9395 \% \mathrm{Cl} 0.66-1.31 ; \mathrm{HR}=0.5695 \% \mathrm{Cl} 0.37-0.84 ; \mathrm{HR}=0.4895 \% \mathrm{Cl} 0.31-0.74$, respectively). There were similar trends in the intake of poultry and aquatic products.

In the highest tertiles of physical activity, a higher intake of red meat, poultry, and aquatic products was associated with a lower risk for all-cause mortality than in the lowest tertiles (red meat, $\mathrm{HR}=0.80,0.62$, 0.51 , and 0.48 ; poultry, $\mathrm{HR}=0.85,0.51,0.48$, and 0.45 ; aquatic products, $\mathrm{HR}=0.80,0.57,0.55$, and 0.40 , respectively). Similarly, there is a protective effect of moderate to high intake of poultry, aquatic products, and eggs on CVD mortality in high physical activity (red meat, $\mathrm{HR}=0.80,0.62,0.53$, and 0.39 ; poultry, $\mathrm{HR}=0.71$, 
$0.54,0.34$, and 0.42 ; aquatic products, $H R=0.62,0.60,0.38$, and 0.29 ; eggs, $H R=0.65,0.45,0.52$, and 0.61 , respectively). However, no associations were observed for all kinds of food, except for poultry and red meat, with cancer mortality (red meat, $\mathrm{HR}=1.12,0.91,0.31$, and 0.81 ; poultry, $\mathrm{HR}=1.18,0.43,0.59$, and 0.80 , respectively). (Fig. 2 and Supplementary Table1).

\section{Discussion}

To the best of our knowledge, this is the first study to investigate the relationships between animal products, such as red meat, poultry, aquatic products, eggs, and physical activity as well as their combined effects on cause-specific and all-cause mortality in T2DM patients in China. In this cohort study, moderate to vigorous physical activity and a high consumption of red meat, poultry, and aquatic products were associated with a lower risk of mortality. When their combined effect was investigated, we discovered a significant relative decrease in all-cause mortality and CVD mortality.

Concerning previous studies in patients with T2DM, several studies have demonstrated that when adjusting for confounding factors [32-34], a high level of physical activity helped reduce the risk of CVD mortality and mortality caused by other reasons, with the highest level of physical activity being connected to a $36 \%$ and $44 \%$ decreased risk of CVD mortality and mortality, respectively, caused by other reasons. However, physical activity may have a different effect on mortality in different studies. This may be partly explained by the different methods of physical activity measurement. In addition, the definition and classification criteria of physical activity were also different.

Previous studies have revealed significant regional variations in the meat-mortality relationship. The majority of the positive connections found between meat consumption and mortality were found in studies conducted in North America and Europe [35-38], whereas results from Asian studies revealed a clear negative association [17, 39]. In T2DM patients, there was a negative correlation between red meat consumption and the risk of all causes of death, which was consistent with the results in Asia. However, such associations between red meat and CVD and cancer mortality were not found in our study. Over the last few years, many chronic disease risk factors in Asian countries, such as obesity, hypertension, and smoking, have become stronger predictors of disease than meat consumption $[39,40]$. On the other hand, the food preparation technique, which is not taken into account in observational prospective cohort studies, might play a role. In addition, confounders such as socioeconomic condition in relation to people's access to meat may be significant, as both people's accessibility to and the availability of food are concerned with their income in the Asia-Pacific region [41], implying that at this stage in the epidemiologic transition, a higher meat intake is likely to be an indicator of other protective elements, such as adequate energy intake and access to medical care.

Several studies demonstrated that higher quantities of consumption of poultry and aquatic products were connected to a decrease in all-cause and CVD mortality risk in our study. This is in agreement with the results of our study. Because subjects who consume more white meat and aquatic products also consume less red meat, it is hard to examine the health effect of white meat consumption. However, people who eat less red meat intend to consume other proteins, including those found in vegetables, which may prevent CVD. However, in contrast to vegetable products, white meat and aquatic products are both quality protein sources. They consist of less fat and a better fatty acid profile (i.e., mostly unsaturated fatty acids) $[42,43]$ than lamb, pork, 
or beef as well as a lower concentration of heme iron, which are good for cardiometabolic health and may aid in cancer prevention and treatment $[44,45]$. Furthermore, instead of red meat, people may choose poultry and fish as lower-fat alternatives because they are not preserved with nitrite-based salts. Substituting these alternatives for packed and red meat may reduce the risk of getting sick and, therefore, prevent premature death caused by CVD or cancer.

Finally, in the highest tertiles of physical activity, more consumption of aquatic products, poultry, and red meat was linked to a lower risk of all-cause and CVD mortality, respectively, compared to the lowest tertiles. Physical activity is linked to all-cause and CVD mortality, and it is crucial in assessing functional status and cardiovascular health $[46,47]$. The level of physical activity is strongly related to objectively assessed cardiorespiratory fitness [46]. As a result, participants who engage in more physical activity may have improved cardiorespiratory endurance and fitness, which may be protective. If one has a fitter body, in particular, he or she is more likely to be metabolically flexible in dealing with physiological stressors caused by packed meat and red meat consumption than people with poorer health [20]. This is in line with other epidemiological and experimental studies that have found that physical activity and cardiorespiratory health help mitigate the effect of risk elements, including alcohol, BMI, and sedentary time, and thus reduce mortality [48-50]. Therefore, we should not only focus on the positive effects of moderate to high meat consumption but also manage behaviors that are beneficial to physical health in a comprehensive manner to effectively reduce mortality.

The study has some limitations. First, because the data of this research only represented Jiangsu Province, the generalizability of the results may be limited. Second, our conclusions apply only to individuals with T2DM and cannot be generalized to other populations. Finally, although some covariates were adjusted, the retrospective method of the food frequency survey and self-reporting history of diseases impeded the avoidance of the possibility of recall bias and other unknown confounding factors, which may have affected the results of the analysis.

\section{Conclusions}

In T2DM patients, adherence to moderate to high consumption of red meat, poultry, and aquatic products was related to lower mortality. Physical activity was also not linearly associated with mortality, with a protective effect observed $>8$ MET-h/d. Finally, our study highlights that better adherence to moderate to high consumption of red meat, poultry, and aquatic products together with engaging in moderate to high levels of physical activity exerts a beneficial effect in lowering cause-specific and all-cause mortality among T2DM in China.

\section{Abbreviations}

BMI Body mass diseases

Cls Confidence intervals

CVDs Cardiovascular diseases 
FFQ Food frequency questionnaire

HRs Hazard Ratios

T2DM Type 2 diabetes mellitus

\section{Declarations}

Authors' contributions Conceptualization, Methodology: Wei Wang, Xunbao Zhang; Data curation, WritingOriginal draft preparation: Chenlu He, Hao Hou, Yifei Pei; Supervision, Validation: Peian Lou, Zhongming Sun and Enchun Pan; Writing- Reviewing and Editing: Qian Chen, Ying Zhang, Jingjing Wang, Jie Tang, Na Yan, Wei Wang.

Funding This work was supported by the National Natural Science Foundation of China [82003484], Natural Science Fund for Colleges and Universities in Jiangsu Province [20KJB330005], General project of philosophy and social science researches for colleges and universities in Jiangsu Province [2020SJA1053], and Jiangsu Province Postdoctoral Science Foundation [2020Z177].

Acknowledgements The authors would like to thank all the participants involved in the survey. The authors would also like to thank the Huai'an Center for Disease Control and Prevention.

Availability of data and materials Data supporting the results presented in the paper are available upon reasonable requests.

Competing interests The authors declare no conflict competing interests.

Ethical approval and consent to participate Approval was obtained from the ethics committee of the Huai'an Center for Disease Control and Prevention and Xuzhou Medical University. The procedures used in this study adhere to the tenets of the Declaration of Helsinki. All participants gave their written informed consent before their inclusion in the study.

Consent for publication Not applicable.

\section{References}

1. Cho NH, Shaw JE, Karuranga S, Huang Y, da Rocha Fernandes JD, Ohlrogge AW, Malanda B: IDF Diabetes Atlas: Global estimates of diabetes prevalence for 2017 and projections for 2045. Diabetes Res Clin Pract 2018, 138:271-281.

2. Wang L, Gao P, Zhang M, Huang Z, Zhang D, Deng Q, Li Y, Zhao Z, Qin X, Jin D et al: Prevalence and Ethnic Pattern of Diabetes and Prediabetes in China in 2013. JAMA 2017, 317(24):2515-2523.

3. Ning G, Bloomgarden Z: Diabetes in China: prevalence, diagnosis, and control. J Diabetes 2013, 5(4):372. 
4. Zhuo X, Zhang P, Hoerger TJ: Lifetime direct medical costs of treating type 2 diabetes and diabetic complications. American journal of preventive medicine 2013, 45(3):253-261.

5. Ang YG, Yap CW, You AX: Lifetime cost for type 2 diabetes mellitus in Singapore. Journal of diabetes 2018, 10(4):296-301.

6. Hirakawa Y, Ninomiya T, Kiyohara Y, Murakami Y, Saitoh S, Nakagawa H, Okayama A, Tamakoshi A, Sakata K, Miura K et al: Age-specific impact of diabetes mellitus on the risk of cardiovascular mortality: An overview from the evidence for Cardiovascular Prevention from Observational Cohorts in the Japan Research Group (EPOCH-JAPAN). Journal of epidemiology 2017, 27(3):123-129.

7. Saran R, Robinson B, Abbott KC, Agodoa LYC, Bragg-Gresham J, Balkrishnan R, Bhave N, Dietrich X, Ding Z, Eggers PW et al: US Renal Data System 2018 Annual Data Report: Epidemiology of Kidney Disease in the United States. American journal of kidney diseases : the official journal of the National Kidney Foundation 2019, 73(3 Suppl 1):A7-a8.

8. Giovannucci E, Harlan DM, Archer MC, Bergenstal RM, Gapstur SM, Habel LA, Pollak M, Regensteiner JG, Yee D: Diabetes and cancer: a consensus report. Diabetes care 2010, 33(7):1674-1685.

9. Salehidoost R, Mansouri A, Amini M, Aminorroaya Yamini S, Aminorroaya A: Diabetes and all-cause mortality, a 18-year follow-up study. Scientific reports 2020, 10(1):3183.

10. Engelmann J, Manuwald U, Rubach C, Kugler J, Birkenfeld AL, Hanefeld M, Rothe U: Determinants of mortality in patients with type 2 diabetes: a review. Reviews in endocrine \& metabolic disorders 2016, 17(1):129-137.

11. Bellou V, Belbasis L, Tzoulaki I, Evangelou E: Risk factors for type 2 diabetes mellitus: An exposurewide umbrella review of meta-analyses. PloS one 2018, 13(3):e0194127.

12. Huang J, Liao LM, Weinstein SJ, Sinha R, Graubard Bl, Albanes D: Association Between Plant and Animal Protein Intake and Overall and Cause-Specific Mortality. JAMA Intern Med 2020, 180(9):1173-1184.

13. Kromhout D, Spaaij CJ, de Goede J, Weggemans RM: The 2015 Dutch food-based dietary guidelines. Eur J Clin Nutr 2016, 70(8):869-878.

14. Petersen KS, Flock MR, Richter CK, Mukherjea R, Slavin JL, Kris-Etherton PM: Healthy Dietary Patterns for Preventing Cardiometabolic Disease: The Role of Plant-Based Foods and Animal Products. Curr Dev Nutr 2017, 1(12).

15. Li B, Zhang G, Tan M, Zhao L, Jin L, Tang X, Jiang G, Zhong K: Consumption of whole grains in relation to mortality from all causes, cardiovascular disease, and diabetes: Dose-response meta-analysis of prospective cohort studies. Medicine (Baltimore) 2016, 95(33):e4229.

16. Aune D, Giovannucci E, Boffetta P, Fadnes LT, Keum N, Norat T, Greenwood DC, Riboli E, Vatten LJ, Tonstad S: Fruit and vegetable intake and the risk of cardiovascular disease, total cancer and all-cause 
mortality-a systematic review and dose-response meta-analysis of prospective studies. Int J Epidemiol 2017, 46(3):1029-1056.

17. Nagao M, Iso H, Yamagishi K, Date C, Tamakoshi A: Meat consumption in relation to mortality from cardiovascular disease among Japanese men and women. Eur J Clin Nutr 2012, 66(6):687-693.

18. Zeraatkar D, Han MA, Guyatt GH, Vernooij RWM, El Dib R, Cheung K, Milio K, Zworth M, Bartoszko JJ, Valli $C$ et al: Red and Processed Meat Consumption and Risk for All-Cause Mortality and Cardiometabolic Outcomes: A Systematic Review and Meta-analysis of Cohort Studies. Annals of internal medicine 2019, 171(10):703-710.

19. Zhong VW, Van Horn L, Greenland P, Carnethon MR, Ning H, Wilkins JT, Lloyd-Jones DM, Allen NB: Associations of Processed Meat, Unprocessed Red Meat, Poultry, or Fish Intake With Incident Cardiovascular Disease and All-Cause Mortality. JAMA internal medicine 2020, 180(4):503-512.

20. Argyridou S, Zaccardi F, Davies MJ, Khunti K, Yates T: Relevance of physical function in the association of red and processed meat intake with all-cause, cardiovascular, and cancer mortality. Nutr Metab Cardiovasc Dis 2019, 29(12):1308-1315.

21. Resnick HE, Foster GL, Bardsley J, Ratner RE: Achievement of American Diabetes Association clinical practice recommendations among U.S. adults with diabetes, 1999-2002: the National Health and Nutrition Examination Survey. Diabetes care 2006, 29(3):531-537.

22. Hamasaki H: Daily physical activity and type 2 diabetes: A review. World journal of diabetes 2016, 7(12):243-251.

23. Liu G, Li Y, Hu Y, Zong G, Li S, Rimm EB, Hu FB, Manson JE, Rexrode KM, Shin HJ et al: Influence of Lifestyle on Incident Cardiovascular Disease and Mortality in Patients With Diabetes Mellitus. Journal of the American College of Cardiology 2018, 71(25):2867-2876.

24. Zhao M, Veeranki SP, Magnussen CG, Xi B: Recommended physical activity and all cause and cause specific mortality in US adults: prospective cohort study. BMJ (Clinical research ed) 2020, 370:m2031.

25. Kraus WE, Powell KE, Haskell WL, Janz KF, Campbell WW, Jakicic JM, Troiano RP, Sprow K, Torres A, Piercy KL: Physical Activity, All-Cause and Cardiovascular Mortality, and Cardiovascular Disease. Medicine and science in sports and exercise 2019, 51(6):1270-1281.

26. Lupoli R, Vitale M, Calabrese I, Giosue A, Riccardi G, Vaccaro O: White Meat Consumption, All-Cause Mortality, and Cardiovascular Events: A Meta-Analysis of Prospective Cohort Studies. Nutrients 2021, 13(2).

27. Medeiros G, Azevedo KPM, Mesquita GXB, Lima S, Silva DFO, Pimenta I, Goncalves A, Lyra CO, Piuvezam G: Red meat consumption, risk of incidence of cardiovascular disease and cardiovascular mortality, and the dose-response effect: Protocol for a systematic review and meta-analysis of longitudinal cohort studies. Medicine (Baltimore) 2019, 98(38):e17271. 
28. American Diabetes A: Diagnosis and classification of diabetes mellitus. Diabetes Care 2013, 36 Suppl 1:S67-74.

29. Cleland CL, Hunter RF, Kee F, Cupples ME, Sallis JF, Tully MA: Validity of the global physical activity questionnaire (GPAQ) in assessing levels and change in moderate-vigorous physical activity and sedentary behaviour. BMC Public Health 2014, 14:1255.

30. Michaelsson K, Baron JA, Byberg L, Hoijer J, Larsson SC, Svennblad B, Melhus H, Wolk A, Warensjo Lemming $\mathrm{E}$ : Combined associations of body mass index and adherence to a Mediterranean-like diet with allcause and cardiovascular mortality: A cohort study. PLoS Med 2020, 17(9):e1003331.

31. Schmidt CO, Ittermann T, Schulz A, Grabe HJ, Baumeister SE: Linear, nonlinear or categorical: how to treat complex associations? Splines and nonparametric approaches. Int J Public Health 2013, 58(1):161-165.

32. Zethelius B, Gudbjornsdottir S, Eliasson B, Eeg-Olofsson K, Cederholm J, Swedish National Diabetes R: Level of physical activity associated with risk of cardiovascular diseases and mortality in patients with type-2 diabetes: report from the Swedish National Diabetes Register. Eur J Prev Cardiol 2014, 21(2):244-251.

33. Bakrania K, Edwardson CL, Khunti K, Henson J, Stamatakis E, Hamer M, Davies MJ, Yates T: Associations of objectively measured moderate-to-vigorous-intensity physical activity and sedentary time with all-cause mortality in a population of adults at high risk of type 2 diabetes mellitus. Prev Med Rep 2017, 5:285288.

34. Glenn KR, Slaughter JC, Fowke JH, Buchowski MS, Matthews CE, Signorello LB, Blot WJ, Lipworth L: Physical activity, sedentary behavior and all-cause mortality among blacks and whites with diabetes. Ann Epidemiol 2015, 25(9):649-655.

35. Pan A, Sun Q, Bernstein AM, Schulze MB, Manson JE, Stampfer MJ, Willett WC, Hu FB: Red meat consumption and mortality: results from 2 prospective cohort studies. Arch Intern Med 2012, 172(7):555-563.

36. Rohrmann S, Overvad K, Bueno-de-Mesquita HB, Jakobsen MU, Egeberg R, Tjonneland A, Nailler L, Boutron-Ruault MC, Clavel-Chapelon F, Krogh V et al: Meat consumption and mortality-results from the European Prospective Investigation into Cancer and Nutrition. BMC Med 2013, 11:63.

37. Abete I, Romaguera D, Vieira AR, Lopez de Munain A, Norat T: Association between total, processed, red and white meat consumption and all-cause, CVD and IHD mortality: a meta-analysis of cohort studies. $B r \mathrm{~J}$ Nutr 2014, 112(5):762-775.

38. Sinha R, Cross AJ, Graubard BI, Leitzmann MF, Schatzkin A: Meat intake and mortality: a prospective study of over half a million people. Arch Intern Med 2009, 169(6):562-571.

39. Lee JE, McLerran DF, Rolland B, Chen Y, Grant EJ, Vedanthan R, Inoue M, Tsugane S, Gao YT, Tsuji I et al: Meat intake and cause-specific mortality: a pooled analysis of Asian prospective cohort studies. Am J Clin Nutr 2013, 98(4):1032-1041. 
40. Zheng W, McLerran DF, Rolland B, Zhang X, Inoue M, Matsuo K, He J, Gupta PC, Ramadas K, Tsugane $\mathrm{S}$ et al: Association between body-mass index and risk of death in more than 1 million Asians. $\mathrm{N} \mathrm{Engl} \mathrm{J}$ Med 2011, 364(8):719-729.

41. Yang RY, Hanson PM: Improved food availability for food security in Asia-Pacific region. Asia Pac J Clin Nutr 2009, 18(4):633-637.

42. Micha R, Michas G, Lajous M, Mozaffarian D: Processing of meats and cardiovascular risk: time to focus on preservatives. BMC Med 2013, 11:136.

43. Nielsen TB, Wurtz AML, Dahm CC, Overvad K, Tjonneland A: Substitution of unprocessed and processed red meat with poultry or fish and total and cause-specific mortality. Br J Nutr 2021:1-7.

44. Farvid MS, Ding M, Pan A, Sun Q, Chiuve SE, Steffen LM, Willett WC, Hu FB: Dietary linoleic acid and risk of coronary heart disease: a systematic review and meta-analysis of prospective cohort studies. Circulation 2014, 130(18):1568-1578.

45. D'Archivio M, Scazzocchio B, Vari R, Santangelo C, Giovannini C, Masella R: Recent Evidence on the Role of Dietary PUFAs in Cancer Development and Prevention. Curr Med Chem 2018, 25(16):1818-1836.

46. Yates T, Zaccardi F, Dhalwani NN, Davies MJ, Bakrania K, Celis-Morales CA, Gill JMR, Franks PW, Khunti K: Association of walking pace and handgrip strength with all-cause, cardiovascular, and cancer mortality: a UK Biobank observational study. Eur Heart J 2017, 38(43):3232-3240.

47. Williams PT, Thompson PD: The relationship of walking intensity to total and cause-specific mortality. Results from the National Walkers' Health Study. PLoS One 2013, 8(11):e81098.

48. McCarthy M, Edwardson CL, Davies MJ, Henson J, Bodicoat DH, Khunti K, Dunstan DW, King JA, Yates T: Fitness Moderates Glycemic Responses to Sitting and Light Activity Breaks. Med Sci Sports Exerc 2017, 49(11):2216-2222.

49. Ekelund U, Steene-Johannessen J, Brown WJ, Fagerland MW, Owen N, Powell KE, Bauman A, Lee IM, Lancet Physical Activity Series 2 Executive C, Lancet Sedentary Behaviour Working G: Does physical activity attenuate, or even eliminate, the detrimental association of sitting time with mortality? A harmonised metaanalysis of data from more than 1 million men and women. Lancet 2016, 388(10051):1302-1310.

50. Moholdt T, Lavie CJ, Nauman J: Interaction of Physical Activity and Body Mass Index on Mortality in Coronary Heart Disease: Data from the Nord-Trondelag Health Study. Am J Med 2017, 130(8):949-957.

\section{Tables}

Table 1. Baseline characteristics of T2DM patients according to survival status 
Variables

\section{Age(years)}

Duration of diabetes (years)

HbA1c (\%)

Gender

Male

Female

Level of education

Primary school or less

Secondary school

High school

College or above

\section{Marital status}

Never married

Married/Cohabiting

Divorced/Widowed/Separated

Household income (yuan)

$\leq 30000$

30000-110000

110000-160000

$\geq 160000$

Frequency of smoking

Current smokers
Former smokers
Never smokers
Frequency of drinking

Current drinkers

Former drinkers

Never drinkers

Sleep duration

\section{Overall}

62.1(55.7.74.3)

$3.0(1.0,7.0)$

$7.2(6.3,8.7)$

Survivors

All-cause deaths

$\mathrm{C}^{2} / \mathrm{Z} \quad P$ 69.7(63.7,72.1) - $-19.903<0.001$

61.5(55.1,67.6)

$4.0(1.0,10.0)$

$-3.627<0.001$

$7.2(6.2,8.7)$

$7.7(6.5,9.3)$

$-6.309<0.001$

$26.703<0.001$

2801(38.3)

2473(37.4)

328(47.4)

4510(61.7)

$4146(62.6)$

364(52.6)

$30.030<0.001$

4958(67.8) $\quad 4431(66.9) \quad 527(76.2)$

1494(20.4)

1373(20.7)

121(17.5)

592(8.1)

561(8.5)

254(3.8)

267(3.7)

73(1.0)

6370(87.1)

868(11.9)

715(10.8)

63(1.0)

10(1.4)

529(76.4)

153(22.1)

$79.012<0.001$

(31.5)

13(1.9)

$10(1.4)$
$529(76.4)$
$153(22.1)$

468(67.6)

210(30.3)

10(1.4)

$4(0.6)$

$58(0.8)$

$54(0.8)$

$29.579<0.001$

1682(23.0) 1492(22.5) 190(27.5)

$387(5.3) \quad 327(4.9) \quad 60(8.7)$

5242(71.7)

$4800(72.5)$

442(63.9)

$2.401 \quad 0.301$

$20.737<0.001$ 


\begin{tabular}{|c|c|c|c|c|c|}
\hline 6-8h/day & $4776(65.3)$ & $4367(66.0)$ & $409(59.1)$ & & \\
\hline$<6$ h/day & $1070(14.6)$ & $962(14.5)$ & 108(15.6) & & \\
\hline$>8$ h/day & $1465(20.0)$ & 1290(19.5) & $175(25.3)$ & & \\
\hline Hypertension & & & & 8.433 & 0.004 \\
\hline Yes & $3578(48.9)$ & $3203(48.4)$ & $375(54.2)$ & & \\
\hline No & $3733(51.1)$ & $3416(51.6)$ & $317(45.8)$ & & \\
\hline Dyslipidemia & & & & 16.258 & $<0.001$ \\
\hline Yes & $1521(20.8)$ & 1418(21.4) & 103(14.9) & & \\
\hline No & $5790(79.2)$ & $5201(78.6)$ & $589(85.1)$ & & \\
\hline Coronary heart disease & & & & 7.628 & 0.006 \\
\hline Yes & $741(10.1)$ & $650(9.8)$ & $91(13.2)$ & & \\
\hline No & 6570(89.9) & $5969(90.2)$ & $601(86.8)$ & & \\
\hline Stroke & & & & 44.718 & $<0.001$ \\
\hline Yes & $882(12.1)$ & $744(11.2)$ & 138(19.9) & & \\
\hline No & 6429(87.9) & $5875(88.8)$ & $554(80.1)$ & & \\
\hline Kidney diseases & & & & 0.285 & 0.593 \\
\hline Yes & 239(3.3) & $214(3.2)$ & $25(3.6)$ & & \\
\hline No & 7072(96.7) & 6405(96.8) & $667(96.4)$ & & \\
\hline Overweight or obesity & & & & 30.600 & $<0.001$ \\
\hline Yes & $5157(70.5)$ & 4732(71.5) & $425(61.4)$ & & \\
\hline No & $2154(29.5)$ & 1887(28.5) & $267(38.6)$ & & \\
\hline
\end{tabular}

Data are expressed median (interquartile range), or $\mathrm{n}(\%)$ where appropriate.

Table 2 Hazard ratios for all-cause mortality according quartiles of red meat, poultry, aquatic products, eggs and tertiles of physical activity. 


\begin{tabular}{|c|c|c|c|c|c|}
\hline $\mathrm{N}$ & 2444 & 2430 & 2437 & & \\
\hline Death & 321 & 218 & 153 & & \\
\hline Person-years & 13901 & 14112 & 14325 & & \\
\hline Crude & 1 & $\begin{array}{l}0.67(0.56- \\
0.79)^{* *}\end{array}$ & $\begin{array}{l}0.46(0.38- \\
0.56)^{\star \star}\end{array}$ & & $<0.001$ \\
\hline $\begin{array}{l}\text { Multivariable } \\
\text { adjusted }^{a}\end{array}$ & 1 & $0.76(0.64-0.90)^{*}$ & $\begin{array}{l}0.63(0.51- \\
0.76)^{\star \star}\end{array}$ & & $<0.001$ \\
\hline $\begin{array}{l}\text { Multivariable } \\
\text { adjusted }^{\mathrm{b}}\end{array}$ & 1 & $0.77(0.65-0.92)$ * & $\begin{array}{l}0.64(0.53- \\
0.78)^{\star \star}\end{array}$ & & $<0.001$ \\
\hline Red meat & Q1 & Q2 & Q3 & Q4 & $\begin{array}{l}P \text { for } \\
\text { trend }\end{array}$ \\
\hline$N$ & 1896 & 2343 & 1485 & 1587 & \\
\hline Death & 220 & 218 & 145 & 109 & \\
\hline Person-years & 10868 & 13608 & 8578 & 9285 & \\
\hline Crude & 1 & $0.79(0.66-0.95)^{*}$ & $0.83(0.68-1.03)$ & $\begin{array}{l}0.58(0.46- \\
0.73)^{\star *}\end{array}$ & $<0.001$ \\
\hline
\end{tabular}

Multivariable

1

$0.79(0.66-0.96) * \quad 1.01(0.81-1.24)$

$0.72(0.57-0.91)$ *

0.005

adjusted $^{a}$

Multivariable

adjusted $^{b}$

$1 \quad 0.82(0.68-0.99)^{*} \quad 1.05(0.85-1.30)$

$0.75(0.59-0.95)$ * $\quad 0.009$

Poultry

Q1 Q2

Q3

Q4

$P$ for

trend

Death

Person-years

$1841 \quad 2161$

1729

1580

$242 \quad 203$

134

113

Crude

$\begin{array}{ll}10487 & 12553 \\ 1 & 0.70(0.58- \\ & 0.84)^{\star *}\end{array}$

Multivariable

adjusted $^{a}$

1

Multivariable adjusted $^{b}$

$0.75(0.62-0.91)$ *

10055

9243

$0.58(0.47-$

$0.53(0.42-$

$0.66)^{\star \star}$

$<0.001$

$0.71)^{\star *}$

$0.62(0.49-$

$0.78)^{* *}$

$\begin{array}{lll}0.65(0.53- & 0.62(0.49- & <0.001 \\ 0.81)^{* *} & 0.78)^{* \star} & \end{array}$

1

$0.78(0.64-0.94)^{*}$

$0.69(0.56-0.86)^{*}$

$0.64(0.51-$

$0.81)^{\text {** }}$

$<0.001$

Aquatic products

Q1 Q2

Q3

Q4

$P$ for trend

$\mathrm{N}$

$2144 \quad 1515$

2293

1359 


\begin{tabular}{|c|c|c|c|c|c|}
\hline Physical activity & Low & Medium & High & & $P$ for trend \\
\hline $\mathrm{N}$ & 2444 & 2430 & 2437 & & \\
\hline Death & 126 & 76 & 48 & & \\
\hline Person-years & 13901 & 14112 & 14325 & & \\
\hline Crude & 1 & $\begin{array}{l}0.59(0.45- \\
0.79)^{\star *}\end{array}$ & $\begin{array}{l}0.37(0.26- \\
0.51)^{\star *}\end{array}$ & & $<0.001$ \\
\hline $\begin{array}{l}\text { Multivariable } \\
\text { adjusted }^{\mathrm{a}}\end{array}$ & 1 & $0.67(0.51-0.90)^{*}$ & $\begin{array}{l}0.53(0.37- \\
0.74)^{\star *}\end{array}$ & & $<0.001$ \\
\hline $\begin{array}{l}\text { Multivariable } \\
\text { adjusted }^{\mathrm{b}}\end{array}$ & 1 & $0.71(0.53-0.95)^{*}$ & $0.56(0.40-0.79)^{*}$ & & 0.002 \\
\hline Red meat & Q1 & Q2 & Q3 & Q4 & $P$ for trend \\
\hline$N$ & 1896 & 2343 & 1485 & 1587 & \\
\hline Death & 77 & 83 & 48 & 42 & \\
\hline Person-years & 10868 & 13608 & 8578 & 9285 & \\
\hline Crude & 1 & $0.86(0.63-1.17)$ & $0.79(0.55-1.13)$ & $\begin{array}{l}0.64(0.44- \\
0.93)^{*}\end{array}$ & 0.123 \\
\hline $\begin{array}{l}\text { Multivariable } \\
\text { adjusted }^{\text {a }}\end{array}$ & 1 & $0.86(0.63-1.17)$ & $0.98(0.68-1.41)$ & $0.81(0.56-1.19)$ & 0.630 \\
\hline $\begin{array}{l}\text { Multivariable } \\
\text { adjusted }^{\mathrm{b}}\end{array}$ & 1 & $0.89(0.65-1.21)$ & $1.06(0.74-1.53)$ & $0.88(0.60-1.30)$ & 0.704 \\
\hline Poultry & Q1 & Q2 & Q3 & Q4 & $P$ for trend \\
\hline$N$ & 1841 & 2161 & 1729 & 1580 & \\
\hline Death & 83 & 79 & 45 & 43 & \\
\hline Person-years & 10487 & 12553 & 10055 & 9243 & \\
\hline Crude & 1 & $0.79(0.58-1.08)$ & $0.57(0.39-0.81)$ * & $\begin{array}{l}0.58(0.40- \\
0.84)^{\star}\end{array}$ & 0.004 \\
\hline $\begin{array}{l}\text { Multivariable } \\
\text { adjusted }^{\text {a }}\end{array}$ & 1 & $0.85(0.62-1.16)$ & $0.66(0.46-0.95)^{*}$ & $0.69(0.48-1.01)$ & 0.095 \\
\hline $\begin{array}{l}\text { Multivariable } \\
\text { adjusted }^{\mathrm{b}}\end{array}$ & 1 & $0.89(0.65-1.22)$ & $0.68(0.47-0.99)^{*}$ & $0.72(0.49-1.05)$ & 0.140 \\
\hline Aquatic products & Q1 & Q2 & Q3 & Q4 & $P$ for trend \\
\hline$N$ & 2144 & 1515 & 2293 & 1359 & \\
\hline Death & 95 & 53 & 71 & 31 & \\
\hline Person-years & 12336 & 8749 & 13305 & 7948 & \\
\hline
\end{tabular}




\begin{tabular}{|c|c|c|c|c|c|}
\hline Crude & 1 & $0.79(0.56-1.10)$ & $0.69(0.51-0.94) *$ & $\begin{array}{l}0.50(0.34- \\
0.76)^{*}\end{array}$ & 0.005 \\
\hline $\begin{array}{l}\text { Multivariable } \\
\text { adjusted }^{\mathrm{a}}\end{array}$ & 1 & $0.78(0.56-1.10)$ & $0.80(0.59-1.09)$ & $\begin{array}{l}0.59(0.39- \\
0.88)\end{array}$ & 0.069 \\
\hline $\begin{array}{l}\text { Multivariable } \\
\text { adjusted }^{\mathrm{b}}\end{array}$ & 1 & $0.81(0.58-1.14)$ & $0.84(0.61-1.15)$ & $\begin{array}{l}0.62(0.41- \\
0.93)\end{array}$ & 0.136 \\
\hline Eggs & Q1 & Q2 & Q3 & Q4 & $P$ for trend \\
\hline $\mathrm{N}$ & 1868 & 2520 & 2451 & 472 & \\
\hline Death & 76 & 81 & 75 & 18 & \\
\hline Person-years & 10823 & 14556 & 14228 & 2731 & \\
\hline Crude & 1 & $0.80(0.58-1.09)$ & $0.75(0.55-1.03)$ & $0.94(0.56-1.57)$ & 0.299 \\
\hline $\begin{array}{l}\text { Multivariable } \\
\text { adjusted }^{a}\end{array}$ & 1 & $0.85(0.62-1.17)$ & $0.86(0.62-1.19)$ & $0.90(0.53-1.51)$ & 0.752 \\
\hline $\begin{array}{l}\text { Multivariable } \\
\text { adjusted }^{b}\end{array}$ & 1 & $0.86(0.63-1.18)$ & $0.85(0.61-1.18)$ & $0.91(0.54-1.54)$ & 0.739 \\
\hline \multicolumn{6}{|c|}{$\begin{array}{l}\text { Multivariable adjusted }{ }^{\mathrm{a}} \text { : Adjusted for age, duration of diabetes, gender, marital status, level of education, } \\
\text { household income and HbA1c. } \\
\text { Multivariable adjusted }{ }^{\mathrm{b}} \text { : Adjusted for age, duration of diabetes, gender, marital status, level of education, } \\
\text { household income, HbA1c, frequency of smoking, frequency of drinking, hypertension, dyslipidemia, coronary } \\
\text { heart disease, kidney diseases, overweight or obesity and sleep duration. }\end{array}$} \\
\hline
\end{tabular}

Table 4. Hazard ratios for cancer mortality according quartiles of red meat, poultry, aquatic products, eggs and tertiles of physical activity. 


\begin{tabular}{|c|c|c|c|c|c|}
\hline Physical activity & Low & Medium & High & & $P$ for trend \\
\hline$N$ & 2444 & 2430 & 2437 & & \\
\hline Death & 83 & 61 & 57 & & \\
\hline Person-years & 13901 & 14112 & 14325 & & \\
\hline Crude & 1 & $0.72(0.52-1.01)$ & $0.67(0.47-0.93)$ * & & 0.035 \\
\hline Multivariable adjusted ${ }^{a}$ & 1 & $0.82(0.59-1.14)$ & $0.87(0.62-1.23)$ & & 0.461 \\
\hline Multivariable adjusted ${ }^{b}$ & 1 & $0.82(0.59-1.15)$ & $0.88(0.62-1.24)$ & & 0.502 \\
\hline Red meat & Q1 & Q2 & Q3 & Q4 & $P$ for trend \\
\hline $\mathrm{N}$ & 1896 & 2343 & 1485 & 1587 & \\
\hline Death & 62 & 59 & 41 & 39 & \\
\hline Person-years & 10868 & 13608 & 8578 & 9285 & \\
\hline Crude & 1 & $0.76(0.53-1.08)$ & $0.84(0.56-1.24)$ & $0.74(0.49-1.10)$ & 0.365 \\
\hline Multivariable adjusted ${ }^{a}$ & 1 & $0.77(0.64-1.10)$ & $0.96(0.65-1.43)$ & $0.82(0.55-1.24)$ & 0.453 \\
\hline Multivariable adjusted ${ }^{b}$ & 1 & $0.79(0.55-1.13)$ & $0.98(0.66-1.47)$ & $0.82(0.54-1.23)$ & 0.502 \\
\hline Poultry & Q1 & Q2 & Q3 & Q4 & $P$ for trend \\
\hline$N$ & 1841 & 2161 & 1729 & 1580 & \\
\hline Death & 71 & 47 & 44 & 39 & \\
\hline Person-years & 10487 & 12553 & 10055 & 9243 & \\
\hline Crude & 1 & $0.55(0.38-0.80)^{*}$ & $0.65(0.44-0.94)^{*}$ & $0.62(0.42-0.92)^{*}$ & 0.006 \\
\hline Multivariable adjusted ${ }^{a}$ & 1 & $0.57(0.40-0.83)^{*}$ & $0.68(0.46-0.99)$ * & $0.65(0.44-0.98)$ * & 0.018 \\
\hline Multivariable adjusted & 1 & $0.58(0.40-0.84)^{*}$ & $0.70(0.47-1.03)$ & $0.65(0.43-0.97)^{*}$ & 0.022 \\
\hline Aquatic products & Q1 & Q2 & Q3 & Q4 & $P$ for trend \\
\hline $\mathrm{N}$ & 2144 & 1515 & 2293 & 1359 & \\
\hline Death & 62 & 59 & 41 & 39 & \\
\hline Person-years & 12336 & 8749 & 13305 & 7948 & \\
\hline Crude & 1 & $1.05(0.71-1.53)$ & $0.87(0.61-1.24)$ & $0.88(0.58-1.32)$ & 0.728 \\
\hline Multivariable adjusted ${ }^{a}$ & 1 & $1.04(0.71-1.52)$ & $0.94(0.65-1.35)$ & $0.95(0.62-1.44)$ & 0.956 \\
\hline Multivariable adjusted ${ }^{b}$ & 1 & $1.06(0.72-1.55)$ & $0.96(0.66-1.38)$ & $0.96(0.63-1.47)$ & 0.963 \\
\hline Eggs & Q1 & Q2 & Q3 & Q4 & $P$ for trend \\
\hline
\end{tabular}




\begin{tabular}{llllll} 
N & 1868 & 2520 & 2451 & 472 & \\
\hline Death & 57 & 71 & 62 & 11 & \\
\hline Person-years & 10823 & 14556 & 14228 & 2731 & \\
\hline Crude & 1 & $0.93(0.65-1.31)$ & $0.83(0.58-1.19)$ & $0.77(0.40-1.46)$ & 0.703 \\
\hline Multivariable adjusted & 1 & $0.96(0.67-1.36)$ & $0.86(0.59-1.24)$ & $0.73(0.38-1.40)$ & 0.711 \\
\hline Multivariable adjusted $^{\text {b }}$ & 1 & $0.95(0.67-1.35)$ & $0.85(0.58-1.23)$ & $0.72(0.37-1.38)$ & 0.680
\end{tabular}

Multivariable adjusted ${ }^{a}$ : Adjusted for age, duration of diabetes, gender, marital status, level of education, household income and $\mathrm{HbA1C}$.

Multivariable adjusted ${ }^{\mathrm{b}}$ : Adjusted for age, duration of diabetes, gender, marital status, level of education, household income, $\mathrm{HbA1c}$, frequency of smoking, frequency of drinking, hypertension, dyslipidemia, coronary heart disease, kidney diseases, overweight or obesity and sleep duration.

${ }^{*} P<0.05 ;{ }^{* *} P<0.001$

\section{Figures}



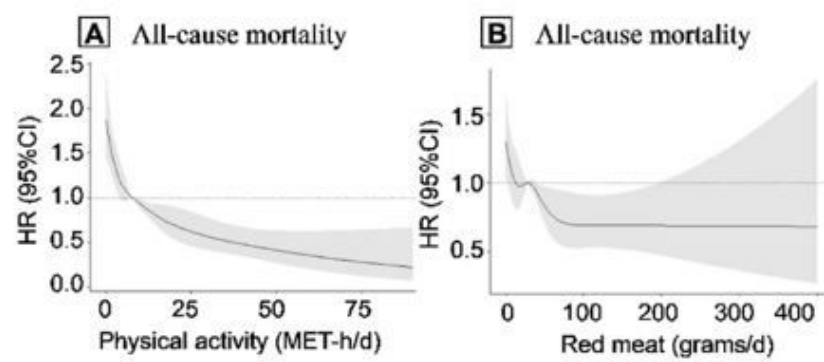

C All-cause mortality

D All-cause mortality

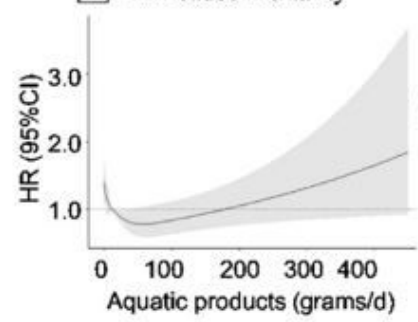

E All-cause mortality
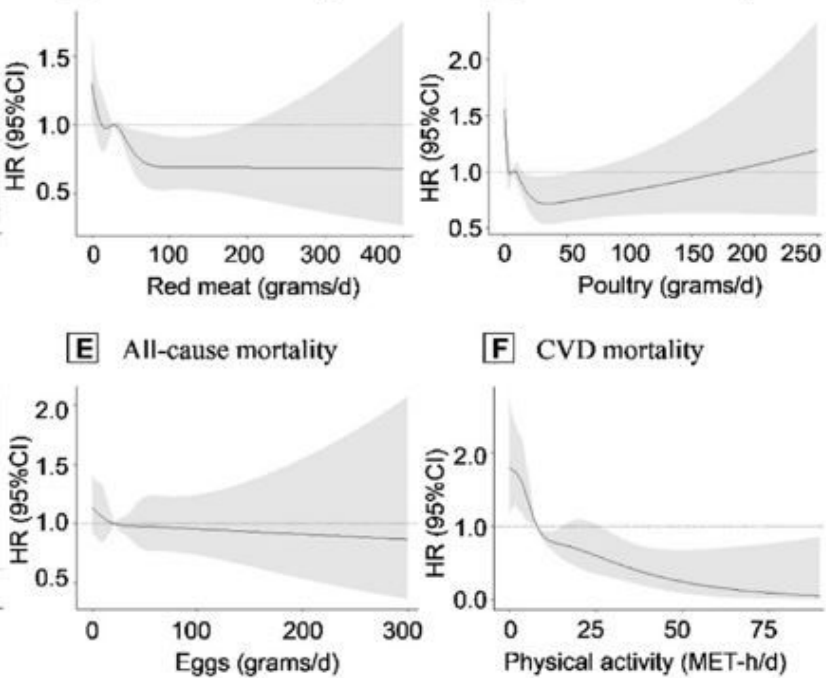

F CVD mortality

G CVD mortality

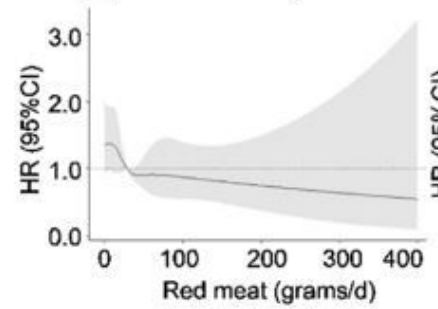

J CVD mortality
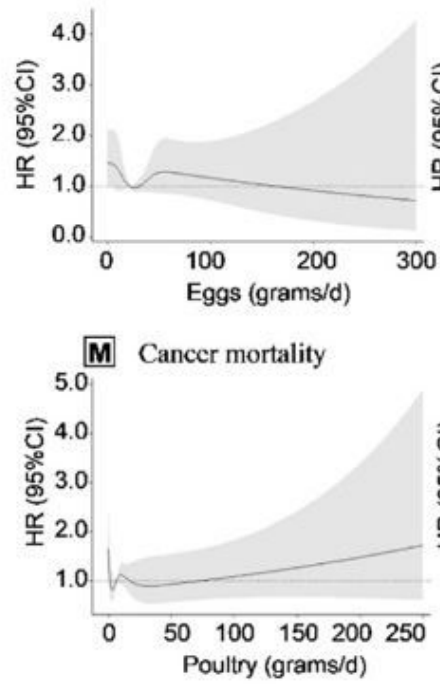

H CVD mortality

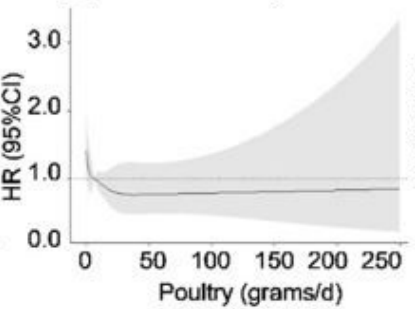

K Cancer mortality

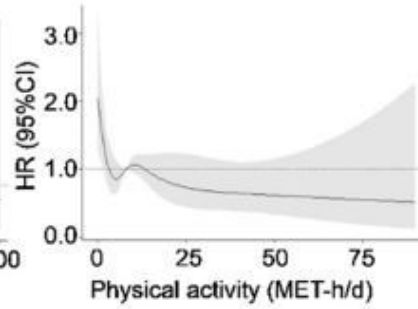

N Cancer mortality

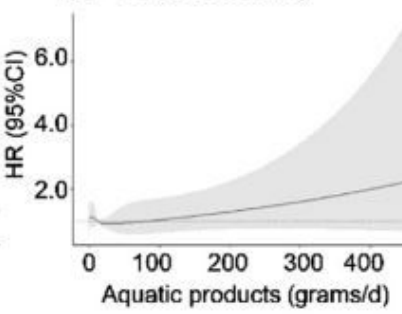

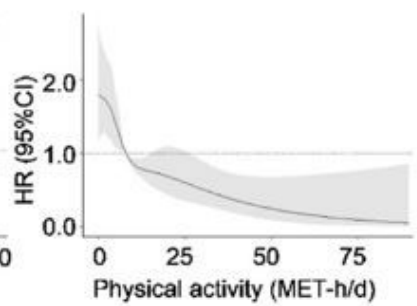

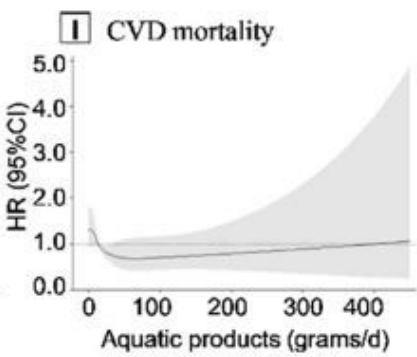

$\square$ Cancer mortality

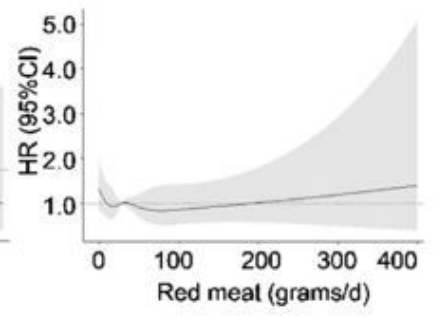

0 Cancer mortality

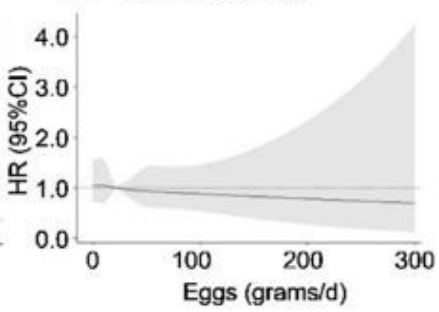

Figure 1

Dose-response relationships between red meat, poultry, aquatic product, egg consumption and all-cause and cause-specific mortality 
A All-cause mortality

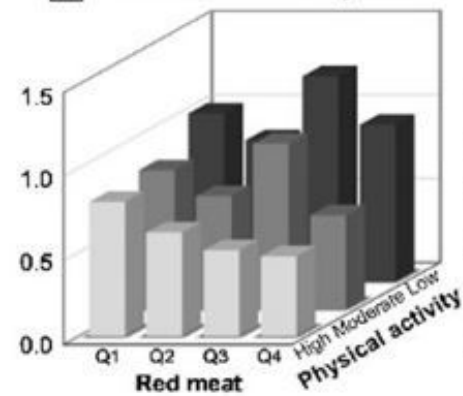

E CVD mortality

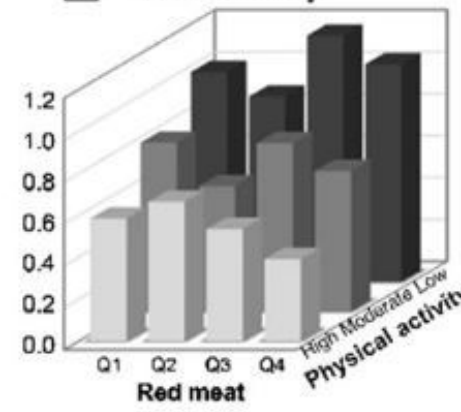

I Cancer mortality

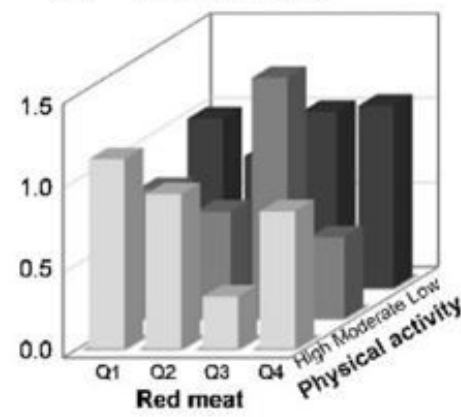

B All-cause morlality

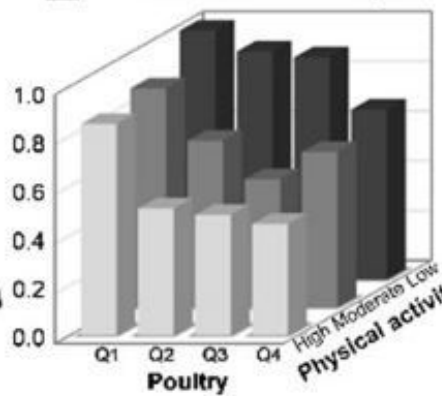

F CVD mortality

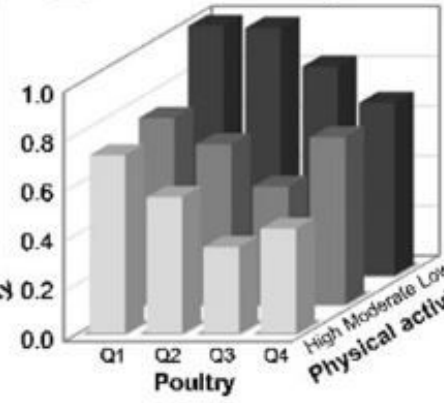

J Cancer mortality

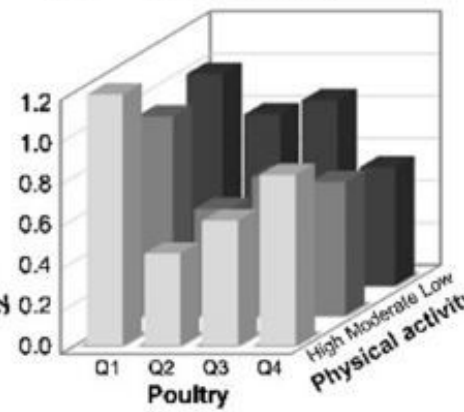

C All-cause mortality

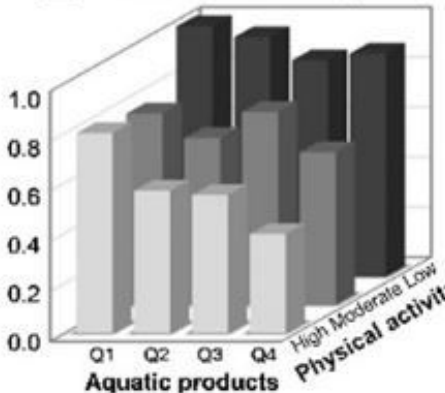

G CVD mortality

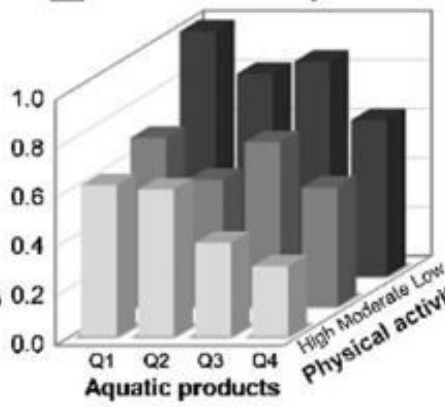

K Cancer mortality

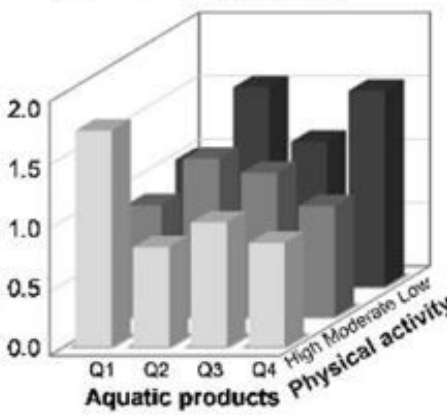

D All-cause mortality

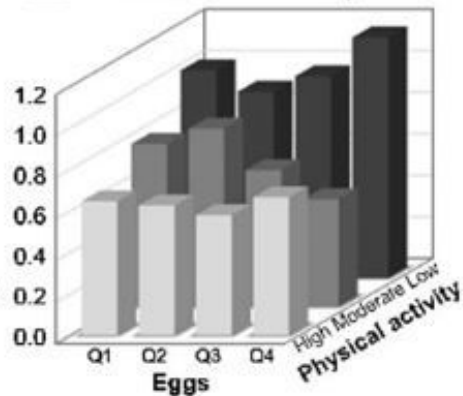

H CVD mortality

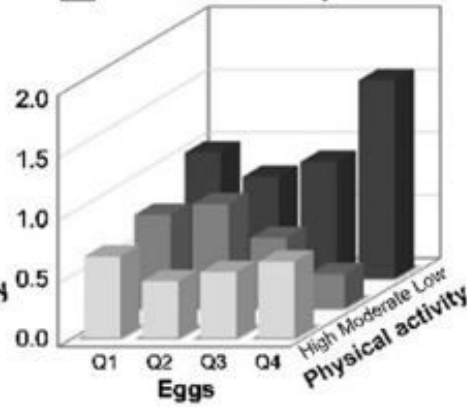

L Cancer mortality

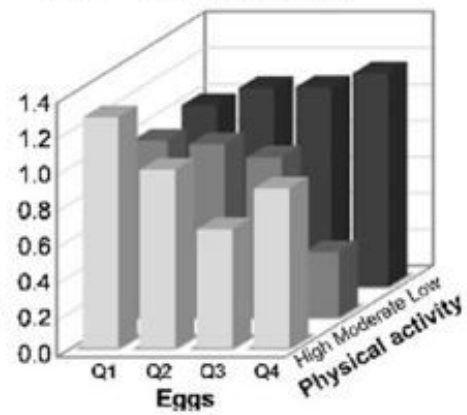

Figure 2

Hazard ratios of the combined effect of quartiles of red meat, poultry, aquatic product, egg consumption and physical activity

\section{Supplementary Files}

This is a list of supplementary files associated with this preprint. Click to download.

- supplementalTables.docx 